\title{
The Study of Potentials and Problems in Reading Faced By the Eighth Grade Students of Junior High School
}

\author{
Ida Ayu Made Istri Utami1, * \\ 1 Universitas Pendidikan Ganesha, Indonesia
}

\begin{abstract}
Knowing students' problems, especially in reading, is very important to design an appropriate and meaningful learning. From the problem identification, teacher can find the potency of designing and developing material to meet students' need. Therefore, this study was aimed to identify the potentials and problems toward reading lesson faced by the eighth grade students of Junior High School. This study was based on the result of classroom observation, document study, and also checklists. The identification of potency and problems through classroom observation was done to obtain data on how existing reading material was used in teaching reading on the classroom. There was also document study to evaluate existing reading material and syllabus used for teaching reading. Then, the data from the teacher and students had been gathered by administering checklists. From the result of the study, it can be identified that the problems faced by the eighth grade students of Junior High School in reading dealt with topic selection, pictures or illustration, and reading activities, while the potency was to develop new reading material by using those problems as consideration.
\end{abstract}

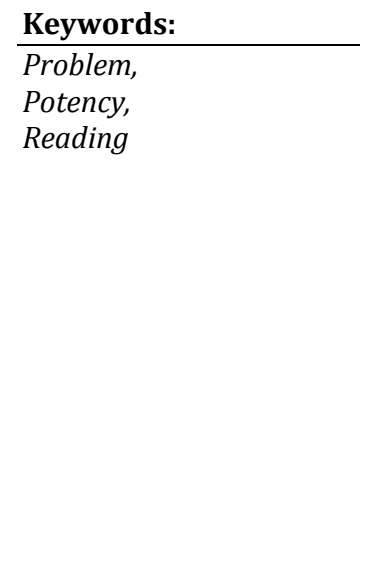

\section{Introduction}

Reading involves both conscious and unconscious thinking process (Beatrice, 1990). The quality of a good reader has good linguistically and conceptually idea with modification of new information.They construct expectationsandpredictions which will be reinforced, modified or challenged reading in the end of reading process. Bartlett (1932) called as schematheory as the world (knowledge and experience) is influenced by the information from the reading text.

Schemata has also been described as cognitive constructs which allow for the organization of information in the long term memory (Widdowson 1983:34). Often a writer will presume that the target reader has the relevant schemata to read the text and will there for eleave certain fact soutorunstated (presuppositions) but this creates problems when the writer and reader do not share the same relevant schema.

There are two types of text used in the reading material which was being developed in this research and development, they are descriptive and recount text. Furthermore, email is introduced as the way to communicate through text by using the internet.

Byrnes (1998) states that traditionally, the purpose of learning to read in a language has been to have access to the literature written in that language. In language instruction, reading materials have traditionally been chosen from literary texts that represent "higher" forms of culture.

He also says that this approach assumes that students learn to read a language by studying its vocabulary, grammar, and sentence structure, not by actually reading it. In this approach, lower level learners read only sentences and paragraphs generated by textbook writers and instructors. The reading of authentic materials is limited to the works of great authors and reserved for upper level students who have developed the language skills needed to read them.

Manzo, Manzo and Albee (2003) states that learning to read involves acquiring and applying strategies for phonetic decoding for building a growing store of sight words, and for reconstructive and

\footnotetext{
* Corresponding author.

E-mail Address: istriutami@undiksha.ac.id (Ida Ayu Made Istri Utami)
} 
constructive comprehension of text.

Furthermore, Byrnes (1998) claims that the communicative approach to language teaching has given instructors a different understanding of the role of reading in the language classroom and the types of texts that can be used in instruction. When the goal of instruction is communicative competence, everyday materials such as train schedules, newspaper articles, and travel and tourism Web sites become appropriate classroom materials, because reading them is one way communicative competence is developed. Instruction in reading and reading practice thus become essential parts of language teaching at every level.

Reading is an activity with a purpose. A person may read in order to gain information or verify existing knowledge, or in order to critique a writer's ideas or writing style. A person may also read for enjoyment, or to enhance knowledge of the language being read. The purpose(s) for reading guide the reader's selection of texts.

The purpose for reading also determines the appropriate approach to reading comprehension. A person who needs to know whether she can afford to eat at a particular restaurant needs to comprehend the pricing information provided on the menu, but does not need to recognize the name of every appetizer listed. A person reading poetry for enjoyment needs to recognize the words the poet uses and the ways they are put together, but does not need to identify main idea and supporting details. However, a person using a scientific article to support an opinion needs to know the vocabulary that is used, understand the facts and cause-effect sequences that are presented, and recognize ideas that are presented as hypotheses and givens.

1. Reading research shows that good readers

2. Read extensively

3. Integrate information in the text with existing knowledge

4. Have a flexible reading style, depending on what they are reading

5. Are motivated

6. Rely on different skills interacting: perceptual processing, phonemic processing, recall

7. Read for a purpose; reading serves a function

Reading is also an interactive process that goes on between the reader and the text, resulting in comprehension. The text presents letters, words, sentences, and paragraphs that encode meaning. The reader uses knowledge, skills, and strategies to determine what that meaning is.

Reader knowledge, skills, and strategies include

1. Linguistic competence: the ability to recognize the elements of the writing system; knowledge of vocabulary; knowledge of how words are structured into sentences

2. Discourse competence: knowledge of discourse markers and how they connect parts of the text to one another

3. Sociolinguistic competence: knowledge about different types of texts and their usual structure and content

4. Strategic competence: the ability to use top-down strategies, as well as knowledge of the language (a bottom-up strategy)

The purposes for reading and the type of text determine the specific knowledge, skills, and strategies that readers need to apply to achieve comprehension. Reading comprehension is thus much more than decoding. Reading comprehension results when the reader knows which skills and strategies are appropriate for the type of text, and understands how to apply them to accomplish the reading purpose.

Berardo (2006) states that there a son for reading depends very much on the purpose for reading. Reading can have three main purposes, for survival, for learnin gor for pleasure. Reading for survival is considered to be in response to our environment, to find out information and can include street signs, advertising, and time tables. It depends very much on the day to day need soft here aderand often involves an immediate response to a situation. In contrast reading for learning is considered to be the type of reading do neinthe classroom an dis goal orientated. While reading for pleasure is something that does not have to be done.

Further more, readers process texts in two ways, either Top-Down or Bottom-Up. Bottom-up processing is when there ader build sup meaning by reading word for word, letter for letter, carefully scrutinizing both vocabulary and syntax. This is often a ssociated with pooror slow readers, but can sometimes occur when there ader sown schema knowledge is inadequate. Top- Down processing is the opposite, where a global meaning of the text is obtained, through "clues" in the text and there ader's good 
schema knowledge. This is often associated with a good reader, who does not read word for word but quickly and efficiently.

In addition, Shriver (2007) claims that reading is actually a complex, multi-part process. Think about each part described below:

a. The words we speak are actually made up of smaller pieces of sound, called phonemes. Understanding that words are made up of individual sounds is a key part of learning to read. This understanding is called phonemic awareness. Phonemes make up spoken words, and words only make sense when these phonemes are combined in a particular order. Phonemic awareness can be taught and learned using activities such as rhyming games.

b. Another part of learning to read is understanding that letters of the alphabet, either by themselves or with other letters, stand for sounds or phonemes. This knowledge is called the alphabetic principle. Real words can be just as new to beginning readers as the made-up words are for those who can read proficiently. Phonemic awareness and phonics skills help readers sound out new words.

c. Knowing that a word has meaning is also a very important part of learning to read. The words we know are called our vocabulary. Learning vocabulary starts very early in life, such as when toddlers look at what you are talking about, or say their first words to get what they need or want. As they grow, they learn more and more words. By the time they start to sound out words as part of learning to read, most children can recognize the words they are sounding out, recognizing that they have heard those words before and what the words mean. This is why having a good vocabulary is so important to reading.

d. As a reader continues to develop phonics skills, he or she improves reading skills to become a more fluent reader. Fluency goes beyond just pronouncing or knowing words it actually includes many parts, such as:

1. Being able to read quickly

2. Recognizing the words and their meanings

3. Saying words and sentences with feeling and stressing the right word or phrase so that a sentence sounds natural

e. Understanding the information that words and sentences are communicating-called comprehension-is another important part of reading. Comprehension is actually the main goal of learning to read. There are many ways to improve comprehension:

1. Building vocabulary can help a reader recognize more words and better understand the overall meaning of the text.

2. Understanding the structure of text-or how it is organized-helps readers know what to expect and where, so they can better comprehend what they are reading. Teachers show students different ways to understand the structure of the text to improve their comprehension.

3. Teachers can give students strategies or guidelines for understanding different types of texts, such as a newspaper, a fiction book, or a menu.

4. Such strategies teach students to ask and answer questions about what they are reading, summarize paragraphs and stories they read, and draw conclusions about the information.

Teaching students to think about what they are reading is an important way for them to use their skills to understand science, history, social studies, math, and many other subjects they will study throughout their education.

\section{Method}

The subjects of this study were the eighth grade students of SMP Laboratorium Undiksha Singaraja and the English teacher who teaches the eighth grade students of SMP Laboratorium Undiksha Singaraja. The identification of potential problems in reading was done through conducting observations. The observation was conducted through classroom observation, document study, teacher's and students' checklist. The classroom observation was done to help the researcher to investigate students' behaviors when learning reading in English by using existing reading material. A study to analyze English teaching documents was also conducted during the document study. The last step of potential and problem identification was giving checklist to the students about their problem toward the use of existing reading material.

Generally, there were some methods of data collection used in this study such as observation, administering checklist, and document study while the instruments used were observation sheet and 
checklist. In this study, the data obtained from observation, interview, and document study, checklist, and test had been analyzed descriptively. The first data was gained through observation. The data of observation had been described in order to know the potency and problem faced in real situation.

The second step was data from document study. The document study contained syllabus analysis step and library research. The data from syllabus analysis, then, had been described qualitatively in order to know the standard competency and basic competence of teaching reading for eighth grade of Junior High School. The result of students' and teacher's checklists were analyzed descriptively to identify the problems and potencies in reading faced by the eighth grade students of Junior High School.

\section{Result and Discussion}

Classroom observation was conducted after sending a permission letter to the principal and after having approval to conduct the research at school. It was done to help the researcher to investigate students' behaviors when learning reading in English by using existing reading material. The observations used observation's sheet as the instrument and it had been conducted to the eighth grader students of SMP Laboratorium Undiksha Singaraja. As the guidance for the researcher to conduct the observation in the classroom, the instrument contained 8 questions. All questions were related to how the existing reading material had been used in the classroom.

Based on the observation, there were two reading materials which had been used in the classroom. They were Language in Focus textbook and workbook. Before the teaching and learning activity being started, the researcher randomly asked some students whether or not they were interested in the reading texts from the textbook and workbook. Most of them answered that they read the text just because they had to, not because they were interested in the text. They listened to the teacher's reading but most of them did not actually pay attention on the content.

The researcher also found that the texts of existing reading material already used some pictures, but they were not colorful. Most of the pictures were presented in simple cartoon illustration for example the uncolored cartoon illustration of two students having conversation. From the observation of students' expression when they were asked to read the text related to the illustration, they did not show excitement on they way they read it and express the intonation of the text. They also did not giving comment on the pictures and illustration on the reading material.

In relation with the appropriateness of the reading material with the students' daily life, the researcher found that some texts on the reading materials were about western culture, and some were about culture from other places in Indonesia. Most students did not have prior knowledge about the text and could not relate the text into their daily life. Only few of the students tried to answer teacher's questions about the text, and most of their answers were incorrect.It took quite amount of time for the teacher to explain the other cultures presented on the text by using Bahasa Indonesia. The researcher also found that the students were hesitating in asking question.Some of them tried their attempt to be actively participated by asking questions which answers can easily be found in the text. Therefore, the teacher asked those students to find the answers by reciting particular sentences from the texts. Those acts showed that the students' questions were not creative enough to reflect students' real curiosity, but simply just to be actively participated on the teaching and learning activity. Moreover, when the teacher encouraged the students to ask questions about the text, the students were busy understanding the concept of western and national culture given earlier by the teacher. It showed that a lot of time was used for culture understanding instead of reading English activities. In additional, students did not express their opinion toward the topics of the reading texts since the topics were not familiar for them.

Moreover, considering the activities occurred in the classroom, it indicated that the activities did not help the students use the target language communicatively in the class. The students were not motivated to interact with friends by using English to discuss about the topic given for reading.

A study to analyze English teaching documents was also conducted. In evaluating the existing reading material, some indicators were used as guidance of the implementation of the checklist. The indicators were adapted from the criteria of good materials by Thomlinson (1993) and they were divided into three categories. The categories were viewed from content, language used, and activities and assessment.The instrument used in gathering the data was checklist. The English teaching document analyzed was the textbook contained reading material for eighth grade students of SMP Laboratorium Undiksha Singaraja

Based on the implementation of the checklist in evaluating the content of the reading material from the textbook used by English teacher of eighth grade students of SMP Laboratorium Undiksha Singaraja, the researcher found that the topics given in the reading text were related to daily activities for the eighth grade students. However, the topics were not related to Balinese culture which is the culture of 
eighth grade students of SMP Laboratorium Undiksha Singaraja. Some of the topics were related to national culture of Indonesia and other topics were related to western culturefor example folklore from British culture, and places of interest in Mesir, Italy, Australia, etc. The other examples of western culture involved in the textbook were the reading texts about Mount Rushmore in USA and The White House in Washington D.C. In those reading texts, the writer gave some explanation of the history of the places which was related to the political development of USA and the changing presidents of the country. Moreover, in the reading texts of biographical recount, the textbook used some famous scientist from biology, physics, and chemistry field of study. It possibly made the students difficult to comprehend the text since they were not familiar with the topics given. Therefore, the contents of reading material were not appropriate with students' prior knowledge.

The researcher also found that the textbook was lack of grammar explanation of the reading text.There was no explanation on the kind of tenses and language features used in the reading text. It possibly made the students difficult to compose their own text because they could not differentiate the characteristics of each genre of texts.

In term of the illustration used in the current textbook, the researcher found that the text book provided sufficient illustrations or pictures. But unfortunately, the pictures were not colorful because they were printed in grayscale.Moreover, some reading text about places in other countries were provided with pictures, on the contrary, some reading text about places and Indonesian culture were not supported with pictures. For example, there was a text about foreigners' holiday in Bali, but the text was not supported by appropriate pictures related to places of interest in Bali, on the other hand, places of interest from other country such as Egypt, Italy, Singapore, China, and Australia were completed with related pictures.

Another point found during the document study was the textbook used formal English with understandable instruction of activities but the instruction did not invite students to actively communicate with each other and with teacher. The level of language used was appropriate with students' level and the vocabulary was not difficult to understand. But unfortunately the activities given did not give students opportunity to refer their own culture and the place where they live. It possibly made the students were not motivated to actively use English in real life interaction.

Beside observation and checklist toward the existing reading material of the textbook used and its implementation, the researcher also had been administered interview to the English teacher. The interview was conducted in order to triangulate some data and avoid the bias of them. These data would be used as consideration in developing the product of culture-based reading material. The instrument used in the interview was an interview guide. There were 20 questions in the interview guide and they were related to the teacher's experience while using the existing reading material from the textbook.

Based on the interview, the English teacher of Class VIII A of SMP Laboratorium Undiksha Singaraja stated that English was students' favorite subject. It could be seen from students' enthusiasm in teaching and learning activities in the classroom. But unfortunately, reading lesson was not students' favorite session of English subject. The students' lack of curiosity of the topic given in reading lesson made them hesitate to ask question about the topic or answer teacher's question.They were passively listen teacher's explanation on the topic of the reading texts. It was probably the impact of most topics given in the reading texts were not familiar for the students. Even though some topics related to students daily activities, but the students did not interested in discussing it with their friends and the teacher. The teacher added that it would be great that he had supplementary reading material with topics related to students' culture and students' daily activities as Balinese. Talking about the presentation of the reading material in the textbook, the teacher admitted that the students never showed their excitement on the pictures given. It was due to the uncolored pictures and illustration used to support the reading text. The teacher also elaborated that the pictures and illustration in the textbook contained no uniqueness to motivated students to develop their curiosity.

In term of the students' attitude during the activities to check their understanding toward the reading text, the teacher said that there was no significant problem.Most of the students were able to answer the questions to check their comprehension as well as the other kind of reading exercises and activities such as matching and completing text with appropriate words. The instruction given in the reading material was clear enough and avoided bias on students' understanding. But the only problem related to reading activities were that the students were not feeling motivated to present or perform their work to the class. When the teacher asked them to loudly state their answer toward the questions given, most of them did not get the challenge. The same case happened when the teacher asked the students to read the text aloud for the class. The teacher assumed that it was happened due to the topics which were not challenging and failed to gain students' interest. 
According to the teacher's confession, it was hard to motivate and encourage the students to give opinion toward the topic.

In this study, another data was collected by using checklist to the students about their problem toward the use of existing reading material. Those questions were derived from some dimensions such as effective domain, cognitive domain, and expectations.

From the result of the checklist, the researcher found that $71.42 \%$ of students stated that they like English. On the other hand, there were $35.71 \%$ of students stated that they did not like reading lesson. The high percentage of students who did not like reading lesson probably because they found that the topic given in the reading text were not interesting, as stated by the English teacher. That fact was supported by the data that showed $71.42 \%$ of the students stated that they did not like the topic given in the reading text. The researcher also found that almost all students stated that the reading texts were not supported with interesting pictures and illustration. Therefore, all students agreed that the reading text should provide colorful pictures and illustration to make them more interested in reading the text.

When the researcher asked about the relation between the topic given in the reading text and the students' daily life, $85.71 \%$ of the students stated that the topics given related to their daily life.

Moreover, the result also showed that $82.14 \%$ of students understand the language used in the reading material. Based on the observation, the students were not actively asked the teacher to explain more about the language used in the reading text. Further, $82.14 \%$ of students stated that they understand the instruction of the reading activities and $28.57 \%$ of students stated that they enjoyed doing the exercises given. That learning attitude probably derived from their lack of curiosity toward the topic given.

Because they were not motivated to participate in class discussion, only $21.42 \%$ of students stated that the reading text stimulated them to give opinion. Based on the observation, the students were not courage to give their opinion toward the topic given. Further, because the students were not stimulated to give opinion, only $32.14 \%$ students stated that they used English to discuss the topic with teacher and other students. Moreover, there were only $42.85 \%$ students stated that the reading material and its activities gave them opportunity to use English as a means of communication. In term of language used in the reading material, $71.42 \%$ of the students stated that the language was difficult to understand. Furthermore, $14.28 \%$ of the students stated that some of the texts were not supported with related pictures. From this study, the researcher found some problems in reading faced by the eighth grade students of Junior High School. The problems dealt with:

1. Topic selection: the students were not interested on the topics presented in the existing reading material. Even though the topics in the existing reading material related to their daily life, but the students admitted that some of the topics were about western culture and the students did not have prior knowledge about it.

2. Pictures and illustration: based on the document study, the researcher found out that the existing reading material already contained a lot of pictures and illustrations. But unfortunately, the pictures and illustration were not colorful and the pictures failed in gaining students attention and interest.

3. Activities in reading: in term of reading activities in the existing reading material, the researcher found that the students were not motivated to express their opinion. Moreover, the students hesitated to answer and ask questions to their teacher.

In addition, the result of the checklist and observation did not show significant problem on the language used in the existing reading material. The language used in the existing material was easy to understand by the students and the instruction of the activities was clear enough. From those problems faced by the students, the researcher identified potencies to develop new reading material by using the problems as consideration.

The new reading material was based on culture because from the result of checklist, the students and teacher of eighth grade of Junior High School agreed that the new developed reading material should relate their culture so they could understand the topics and help them to improve their English. Moreover, by considering the problems in reading faced by the eighth grade students of Junior High School, some potencies in developing reading material were:

1. The reading material should contain interesting topics and closely related to students' culture which is Balinese culture. By using Balinese culture in the topic selection, the students were having prior knowledge on the topics given and they can relate the topics into their daily life.

2. The reading material should supported by colorful pictures and illustration to gain students' interest. 
3. The activities in the reading material should encourage the students to express their opinion and actively use English to communicate with teacher or other students.

Furthermore, the researcher found the researcher found out that the use of language in the reading material should meet the students' level of English so they would not have difficulties to understand the language in the text and instruction

\section{Conclusions and Suggestion}

The general result of observation toward the implementation of existing reading material was that the topics given on the reading texts were not familiar for the students.

Moreover, considering the activities occurred in the classroom, it indicated that the activities did not help the students use the target language communicatively in the class. The students were not motivated to interact with friends by using English to discuss about the topic given for reading.

From those problems faced by the students, the researcher identified potencies to develop new reading material by using the problems as consideration. In relation to the results of this research, the researcher suggest for the English teachers could actively find reading texts which are closely related to students' daily lie and their culture. Through that strategy, the teacher can easily gain students interest and motivate their use of English in active communication.

\section{References}

Beatrice, S. Mikulecky. (1990). A Short Course in Teaching Reading Skills. USA: Addison-Weasley Publishing Company

Berardo, SachaAnthony. (2006). TheUseofAuthenticMaterialsintheTeachingofReading. The Reading Matix Goodman,K.

(1988).TheReadingProcessinCarrell,P.L.,Devine,J.\&Eskey,D.E.(Editors)(1988)InteractiveApproache stoSecondLanguageReadingCambridge,C.U.P.pp11-21

Manzo, A. V., Manzo, U. C., and Albee, J.J. (2004). Reading Assessment for Diagnostic-Prescriptive Teaching. Canada: Thomson Wadsworth

Nuttall, C. (1996). Teaching reading Skills in a foreign language (New Edition) Oxford Heinemann

Tomlinson, Brian. 1998. Materials Development in Language Teaching. United Kingdom: Cambridge University Press.

Widdowson,H.G.1983. LearningPurposeandLanguageUseOxford,O.U.P 